\title{
Os MOVIMENTOS ANTI-SISTÊMICOS: CONJUNTURA DE LUTAS OU IMPASSES POLÍTICOS IDEOLÓGICOS?
}

\section{Giane Alves de Carvalho ${ }^{1}$}

\begin{abstract}
RESUMO
Os chamados movimentos anti-sistêmicos vêm, segundo Wallerstein, se intensificando cada vez mais nos tempos atuais. As contradições, conflitos e tensões, frutos da hegemonia do capital, permitiram uma ressignificação dos movimentos sociais, visando articular novas lutas numa perspectiva mundial, ou seja, a globalização do capital possibilitou a globalização dos movimentos antisistêmicos. No momento em que os movimentos anti-sistêmicos são vistos como principal referência para a incessante luta contra o capital, questiona-se aqui, afinal, o que vem a ser um movimento anti-sistêmico. Apesar das evidências de seu surgimento, em que sentido é possível afirmar sua legitimidade? Nesta luta, quem é o verdadeiro inimigo? Desta forma, tem-se como objetivo discutir, sob uma abordagem crítica e reflexiva, uma breve evolução histórica dos movimentos antisistêmicos, as linhas conceituais, os rumos e impasses políticos ideológicos dos chamados movimentos anti-sistêmicos.

Palavras-chave: Movimentos anti-sistêmicos. Movimentos sociais. Globalização.
\end{abstract}

\begin{abstract}
What are referred to as anti-systemic movements have been getting increasingly intense, according to Wallerstein, in recent times. The contradictions, conflicts
\end{abstract}

${ }^{1}$ Doutoranda em Sociologia Política pela Universidade Federal de Santa Catarina. 
and tensions that are the fruit of the hegemony of capital have permited a resignification of social movements, which have tried to articulate new struggles on a global level. In other words, the globalization of capital has made possible the globalization of anti-systemic movements. At the moment in which antisystemic movements are seen as the principle reference for the incessant struggle against capital, we question what an anti-systemic movement really is. Despite the evidence of their rise, in what sense is it possible to affirm their legitimacy? In this struggle who is the real enemy? Therefore, our objective is to discuss, from a critical and reflexive perspective, the paths and political and ideological impasses of anti-systemic movements.

Keywords: Anti-systemic movements. Social movements. Globalization.

\section{INTRODUÇÃO}

Em tempos contemporâneos, a noção de movimento anti-sistêmico é defendida por Immanuel Wallerstein, sob uma constante articulação com os conceitos de sistema-mundo e capitalismo sistêmico. Tal perspectiva teórica é tomada como ponto de partida para compreender as atuais configurações destes movimentos anti-sistêmicos.

Segundo Wallerstein (1988, p. 587), vivemos numa era de manifestações anti-sistêmicas. A conseqüência resultante dessa expansão das tensões e aprofundamento das contradições tem sido o crescimento dos movimentos antisistêmicos em escala mundial. "Movimentos de libertação nacional, insurgências proletárias, resistências e desafios civilizacionais, contraculturas, revigoramento de religiosidades," são alguns exemplos lembrados pelo autor.

A Conferência Intergaláctica pela Humanidade e contra o Neoliberalismo, organizada pelo Exército Zapatista de Libertação Nacional (EZLN) em 1996 no estado de Chiapas, no México, é considerada como o "marco zero" na linha de organização anti-sistêmica por parte de grupos sociais na América Latina neoliberal (LUIGI; PENNAFORTE, 2005).

Já a reunião ministerial da Organização Mundial do Comércio (OMC) em Seattle ${ }^{2}$, nos Estados Unidos, em novembro de 1999, marcou o nascimento do movimento antiglobalização como uma força internacional. E, por mais que

\footnotetext{
${ }^{2}$ Cerca de 100 mil manifestantes foram às ruas de Seattle protestar contra 0 encontro, que só ocorreu após a prisão de mais de 600 manifestantes.
}

OS MOVIMENTOS ANTI-SISTÊMICOS: CONJUNTURA DE LUTAS ... 
os manifestos antiglobalização em Seattle sejam considerados a marca desse tipo de atuação no mundo atual, o primeiro Fórum Social Mundial (FSM) em Porto Alegre, em 2001, remete muito mais à iniciativa mexicana. Ou, ao menos, é assim que deveria ser, mas, na prática, pouco se evoluiu desde o evento de 2001 (LUIGI; PENNAFORTE, 2005).

Desta forma, é possível constatar, a priori, que os movimentos antisistêmicos englobam, atualmente, uma série de manifestações anti-hegemônicas, numa luta incessante contra o capital e o modelo neoliberal, visando à busca de alternativas para a construção de uma nova estrutura social e uma redefinição na arena econômica e política.

\section{Os Movimentos Sociais e os Movimentos ANTI-SISTÊMICOS: UMA PERSPECTIVA HISTÓRICA}

Segundo Wallerstein (2005), desde a década de 60, os movimentos antisistêmicos são divididos em dois tipos diferentes: os chamados movimentos sociais e os movimentos nacionais. 0 termo movimentos sociais refere-se às organizações sindicais e aos partidos socialistas, tendo como objetivo impulsionar a luta das classes contra a burguesia e contra os empresários no interior de cada Estado. Já os movimentos nacionais buscavam a criação de um Estado nacional, pelo agrupamento de unidades políticas pertencentes à nação e independência de Estados que eram considerados impérios opressores da nacionalidade.

Neste sentido, Wallerstein evidencia que a situação mundial destes movimentos na década de 60 se caracterizou primeiro pelo aspecto das semelhanças entre os movimentos; segundo pelo fato destes movimentos chegarem ao poder e terceiro por não conseguirem transformar o mundo.

A conclusão dos povos do mundo sobre a performance dos clássicos movimentos anti-sistêmicos no exercício do poder foi negativa. Perderam não somente sua crença de que o futuro seria glorioso, mas também a confiança nestes movimentos; deixaram de crer que estes partidos os conduziriam a um mundo mais igualitário. E por terem perdido sua fé neles, perderam também sua fé nos Estados como mecanismos de transformação (WALLERSTEIN, 2005, p. 269).

No entanto, Wallersein esclarece que, desde 1968, tem havido uma busca persistente por um novo e melhor modelo de movimento anti-sistêmico, pois a velha esquerda havia falhado por não aplicar a doutrina da revolução. Houve 
quatro tipos de tentativas de movimentos anti-sistêmicos, algumas ainda em curso: (1) surgimento dos múltiplos maoísmos, inspirados na Revolução Cultural Chinesa, movimentos que não existem mais; (2) o surgimento da New Left (nova esquerda), os Verdes e outros movimentos ecológicos, os movimentos feministas, os movimentos de minorias raciais/étnicas, com destaque maior a partir dos anos 1970; (3) emergência de movimentos de organizações de direitos humanos, adquirindo maior força a partir dos anos 80; (4) movimentos antiglobalização, com maior força a partir dos anos 90.

Sendo assim, os movimentos anti-sistêmicos na atualidade se apresentam de uma forma muito diferente dos movimentos dos séculos XIX e XX. Para o autor, a estratégia em duas etapas da velha esquerda tem se tornado bastante irrelevante. Estamos passando por um período de transição sistêmica que permeia a própria idéia de estratégia anti-sistêmica. Portanto, destaca-se a urgente necessidade de um debate sobre o período de transição sistêmica (WALLERSTEIN, 2005).

Wieviorka (2006) também faz um resgate histórico dos movimentos sociais e reconhece, na mesma perspectiva de Wallerstein, o surgimento de um novo modelo de movimento. Para o autor, o movimento operário foi um paradigma fundador dos movimentos sociais historicamente estabelecidos até meados da década de 60. No entanto, com a desestruturação do movimento operário, um outro modelo de movimento social entrou em cena ao longo das décadas de 1970 e 1980 .

Wieviorka adota a mesma conotação de Touraine (2006) e Melucci (1999) a caracterizar estes movimentos como "Novos Movimentos Sociais", diferentemente da classificação de Movimento Anti-sistêmico de Wallerstein; estes movimentos trouxeram à tona novas contestações no seio da sociedade, em que encontravam um novo elã distinto do movimento operário, caracterizado por uma forte carga cultural; uma nova relação com a política ao se aproximar da esfera pública e privada; um adversário social menos claramente identificável; e uma ênfase na subjetividade dos atores pessoais e coletivos.

Separa Wallerstein (2005) os movimentos sociais assumem uma perspectiva anti-sistêmica, para Wieviorka (2006) os novos movimentos sociais possuem duas faces, entre as quais a primeira é positiva, capaz de formular um projeto, uma utopia, aceitando de bom grado a negociação e que se opõe a um adversário claramente definido; a segunda não possui um princípio positivo, portado por atores caracterizados pela ausência de recursos econômicos, simbólicos, culturais, 
políticos; caracteriza-se por condutas de ruptura em que não existe um adversário claramente definido.

Diferentemente de Wallerstein, este autor percebe que todo movimento assumido em nome de um projeto que se reduz a destruição da ordem estabelecida, o qual não possui adversário e sim inimigo, não é portador de um projeto, mas de uma ideologia delirante.

Neste sentido, o movimento é caracterizado como antimovimento social, pois, segundo o autor, "éa inversão do movimento social, que se torna uma ideologia cada vez mais separada da população que ela pretende encarnar e mobilizar" (WIEVIORKA, 2006, p.108). A inversão também traz à tona a artificialidade destes movimentos ao colocar em primeira instância uma pretensão histórica que não corresponde mais as suas expectativas concretas passando a se constituir num movimento social impossível.

Sendo assim, o autor vem fazendo um paralelo entre a decadência histórica do movimento operário e a ascendência dos antimovimentos. Nesta relação, a questão geracional está presente quando o autor se remete aos jovens como integrantes dos antimovimentos.

No diálogo com Alain Touraine e François Dubet, o autor evidencia que os jovens, frutos de pais operários que tramitaram diante da desestruturação do movimento operário, acabaram por se refugiar em condutas típicas dos antimovimentos sociais.

0 terrorismo italiano dos anos 70, por exemplo, é penetrado por jovens, que "visam viver de outra maneira, cuja cultura reclama uma autonomia pessoal, comunicação e relação, uma juventude que se sente estrangeira em sua própria sociedade" (p. 108). São jovens portadores da cólera social dos excluídos, sem expectativas, mas que querem consumir; porém, o que lhes sobra é raiva e vontade de recorrer às armas.

Nos subúrbios na França nos anos 80, os jovens também mergulham na delinqüência passando pela autodestruição, sentimento de raiva e, por vezes, a ação organizada contra o racismo, formando o que Dubet chamava de "galeras" dos jovens.

Para Wieviorka (2006), o movimento social, quando existe, traz um princípio de conflitualidade que estrutura a vida coletiva; quando ele declina, este princípio desaparece e desenvolvem-se, em seu lugar, condutas de outra 
ordem, como a delinquiência, o racismo, o ódio. Desta maneira, anunciam atores inexistentes e impossiveis que demarcam os antimovimentos sociais com atores atrelados a um sentimento de déficit e de uma falta de comunidade.

No entanto, se tomarmos a perspectiva de movimento anti-sistêmico de Wallerstein (2005), é importante destacar que o autor não se refere a um movimento de ruptura que traz consigo as marcas da violência e da desordem. Apesar de Wallerstein apostar nos movimentos de antiglobalização, suas definições sobre movimento anti-sistêmico evidenciaram uma ampla generalização dos movimentos sociais da atualidade.

E se por um lado é evidente para Wallerstein (2005) a necessidade de lutar contra o capital e o modelo neoliberal, por outro lado, ainda não está clara a especificidade do movimento anti-sistêmico em buscar compreender mais a fundo o que se compreende pela luta contra 0 sistema capitalista, questão que será abordada mais adiante.

Desta forma, pode-se perceber, historicamente, uma ressignificação dos movimentos sociais que acompanha todas as tentativas teóricas para analisar estes movimentos sobre duas características distintas: uma visão marxiana dos movimentos sociais na tentativa de apostar numa visão anti-sistêmica tomando como referência a perspectiva de Wallerstein; euma visão de um estilo habermasiano quando se situa os movimentos sociais num constante diálogo entre esfera pública e privada. A abordagem destes movimentos numa perspectiva histórica também requer que olhemos para os principais dilemas contemporâneos, tanto empíricos quanto teóricos.

Nancy Fraser (2001) identifica na entrada deste novo século, a problemática política das ações coletivas em dois eixos conflitantes: de um lado, a luta por reconhecimento das diferenças de grupos mobilizados sob as bandeiras da nacionalidade, etnicidade, raça, gênero e sexualidade; de outro lado, a clássica luta por redistribuição econômica que visem combater a desigualdade material exacerbada na renda, na posse de propriedades, no acesso ao trabalho e na luta por direitos universais.

A autora situa os dilemas de redistribuição e reconhecimento na relação com as injustiças culturais versus injustiças econômicas. No entanto, para Fraser, estas lutas são costumeiramente dissociadas, pois o particular se contrapõe ao universal; enquanto o primeiro caso tende promover a diferenciação, o outro visa combatê-la. Em parte significa descobrir como manter o reconhecimento cultural 
e igualdade social de forma que ambos se sustentam e não enfraqueçam um ao outro.

Se, por um lado, o reconbecimento de noções de identidade, diferença e dominação cultural é incompatível com a noção de redistribuição enraizada na estrutura político-econômica da sociedade, Frazer deixa claro que este impasse ocorre no campo teórico-normativo e que no mundo real economia política e cultural está interligada, assim como, injustiças de redistribuição e reconhecimento e, portanto, é preciso repensar a possibilidade de articulação entre ambos.

Nestedecursodeevolução históricaedivergênciano campo teórico-empírico, é possível perceber que a luta dos atores é o pano de fundo para a emergência das diferentes categorias sociológicas de movimentos sociais na atualidade; a noção de movimento anti-sistêmico de Wallerstein (2005), o antimovimento social de Wieviorka (2006), os Novos Movimentos Sociais de Touraine (2006) e Melucci (1999) e as ações coletivas de Fraser (2001). A luta é um fator comum destas perspectivas e assegura nosso viés para pensar na noção de movimento antisistêmico a fim de analisar a roupagem e os possíveis rumos de lutas contra a globalização do capital.

\section{As Múltiplas Faces dos Movimentos ANTI-SISTÊMICOS}

Wallerstein (1988) evidencia que a perspectiva do sistema mundo é um fator crucial para compreender os movimentos anti-sistêmicos. Para o autor, a teoria mundial-sistêmica é regida pela constante acumulação de capital, pois atualmente, o mundo é a única unidade de análise possível, todos os elementos que compõem o sistema devem estar interligados e todos os eventos que ocorrem no sistema devem ter explicações internas ao mesmo tempo.

Bastante próximo das proposições de Marx, segundo Wallerstein, a análise sistêmica deve ter uma perspectiva histórica sobre a evolução do capitalismo e uma perspectiva geográfica, pois é preciso que seu estudo seja baseado em um sistema fechado. 0 primeiro e mais fundamental aspecto é que o "moderno sistema-mundo é uma economia-mundo capitalista", inseparável, portanto, de sua estrutura política, composta de múltiplos estados em uma única economia.(WALLERSTEIN, 1996).

Por outro lado, a resposta sistêmica tem sido sempre "cooptação" ou repressão, situação insustentável no longo prazo. Tal processo é contraditório, na 
medida em que cada vez mais as decisões sobre a ação estatal estão submetidas aos ditames do grande capital. Nesse sentido, o modelo político da globalização é antidemocrático em essência, pois desloca as tomadas de decisão a um plano inacessível, a mesmo tempo, em que mantém a rotina dos processos eleitorais circunscritos a temas nacionais ou propostas de reformas sociais, muitas das quais sem possibilidades práticas de serem efetivadas (WALLERSTEIN, 1988, p. 587).

Para Sader (2004), a questão política e teórica mais importante atualmente, na luta por "um outro mundo possível", é aquela referente à construção de uma hegemonia alternativa ao modelo neoliberal. Este revela sinais claros de esgotamento, a hegemonia norte-americana demonstra seus limites, o Fórum Social Mundial (FSM) se afirma como espaço de intercâmbio e de debate dos temas ligados a uma hegemonia alternativa, porém não surge ainda um modelo alternativo, nem como projeto teórico e político, nem como governos que materializem a saída do modelo atual.

0 caráter profundamente contraditório da hegemonia atual no mundo termina provocando enfoques unilineais que, ao invés de favorecer a construção de um mundo articulado de forma democrática, com uma hegemonia construída na base do consenso múltiplo e pluralista, impõe soluções unilaterais e baseadas na força (SADER, 2004).

Estamos assistindo à construção de um império mundial norte-americano em pugna inevitável com outros impérios, dada sua crescente apropriação e dominação de territórios, recursos e populações, bem como o fato de que apareça como o beneficiário principal da nova acumulação original e ampliada de capitais, formulando problemas de insegurança às grandes potências e às potências intermediárias. De fato, tal projeto articula cada vez mais o imperialismo ao capitalismo, até tornar cada um deles incompreensível sem o outro (CASANOVA, 2005).

Negri e Hardt (2000) contestam a noção de imperialismo e a substituem por império, propondo lutar por uma "cidadania global" em vez de lutar pelo poder do Estado, uma vez que a dispersão da "multidão" prevalece sobre a idéia de centralidade da classe trabalhadora. Neste contexto, Hardt e Negri consideram que a luta por justiça social e econômica também deve adotar uma nova forma, no sentido de criar novos conceitos para dar conta da nova realidade, redefinindo o objeto de luta política das massas e "descentralizando" os agentes históricos da transformação socialista. 
No entanto, por trás dos desejos de derrubada da hegemonia capitalista, seja por meio das lutas dos trabalhadores, seja numa perspectiva contemporânea, das lutas dos atores sociais coletivos, ainda se constata uma carência de reflexões sobre como será as outras formas alternativas e se a humanidade está ou não preparada para enfrentar os novos modelos que permitem realizar os "sonhos" de uma sociedade justa e igualitária.

Neste caso, Arrighi (1994) menciona que a questão central do século XXI é a de saber se a renovação/transformação do sistema social mundial no sentido de uma maior igualdade e democracia ainda exige o exercício de uma função piemontesa e, se isto for verdade, qual o Estado ou a coalizão de Estados que terá efetivamente as condições e as disposições necessárias para exercê-la.

Neste contexto, é possível evidenciar um desgaste político e pragmático da esquerda partidária. 0 novo quadro da mundialização do capital e seu reordenamento político e econômico também permitiu uma reconfiguração dos movimentos anti-sistêmicos abarcando novas formas de lutas sociais e novos reclames de justiças sociais.

No entanto, Wallerstein (2003) afirma que se quisermos debater o advento de um mundo novo, no século XXI, é da crítica à consciência histórica da burguesia européia que devemos partir, tal como se propôs Marx. Devemos também ver como é que as pessoas que foram vítimas da má distribuição se comportaram, com vista a minimizarem as suas perdas e a transformarem este sistema, responsável pelas injustiças.

No capitalismo histórico, como é que as pessoas ou grupos conduzirão as suas lutas políticas? A política consiste em mudar as relações de poder numa direção mais favorável aos interesses próprios, redirecionando assim os processos sociais. 0 sucesso na política depende da existência de alavancas de mudança, capazes de proporcionarem vantagem máxima para um mínimo de investimento (WALLERSTEIN, 2001).

Diferentemente de Negri e Hardt (2000), para Wallerstein (2003), a aposta está nas lutas de classes. 0 autor propõe uma mudança para acabar com a relação de exploração, quebrando com os ciclos interligados e sucessivos, próprios do capitalismo. Este autor ainda afirma que esta mudança deve ser do sistema e não dentro do sistema para realmente acabar com as relações de explorações, evitando que o capitalismo se adapte a essas novas mudanças. 
No entanto, quando se fala em luta contra o capitalismo, as interpretações são múltiplas, pois afinal o que podemos compreender por luta contra o capitalismo sistêmico, ou como queira Wallerstein, uma luta que não seja dentro do sistema? Os caminhos são múltiplos e as abordagens se diferem desde a necessidade da implantação do socialismo à criação de um novo modelo que assegure a "ordem" mundial.

Se pela obviedade do "atual estado de coisas", é mais comum encontramos perguntas do que respostas, talvez não seja tão percebível que as perguntas requerem certa ordem ou talvez cautela, quando se questiona se o desgaste políticoideológico de princípios marxistas de emancipação social subentende vivermos num mundo sem atores sociais? Qual o lugar das lutas anticapitalistas?

Primeiramente, há de se considerar que, nesta incessante luta contra 0 capital, na prática, os movimentos anti-sistêmicos assumem múltiplas formas. Nem sempre o que está em jogo é a derrubada da hegemonia dos blocos capitalistas ou a tentativa de por em prática os ideais socialistas via partidos políticos, sob a ânsia da derrubada do neoliberalismo e da hegemonia capitalista.

Enquanto Wallerstein (1996) alerta para a necessidade de pensarmos numa estratégica de transição sistêmica, Negri e Hardt (2000) vêem uma rebelião e mobilização da "multidão" já promovendo a transição. Para Negri (2002), a consequiência das crises é a abertura de novas possibilidades de protestos anticapitalistas, o que confere ao sujeito político um significado maior.

Além disso, Wallerstein (2003) aposta nas lutas de classe como atores internacionais. Entretanto, Negri e Hardt (2000) vão além, atualizando a composição da classe trabalhadora contemporânea. Eles, na verdade, ampliam a esfera da luta de classes e incluem todo o domínio social. A noção de luta de classes é expandida incluindo todas as dimensões da vida cotidiana.

As velhas análises do imperialismo não serão suficientes aqui, porque no final elas não enfrentam o desafio da análise da subjetividade e se concentram antes nas contradições do próprio desenvolvimento do capital. Neste sentido, os autores vêem a necessidade de identificar um esquema teórico que insira a subjetividade dos movimentos sociais do proletariado no centro do processo da globalização e da constituição da ordem mundial (NEGRI; HARDT, 2000, p. 235).

Diante disto, não se nega a importância dada por Wallerstein aos movimentos anti-sistêmicos, guiada pela sua importância histórica e pertinência 
de sua articulação teórico-empírica; porém, direciona-se aqui uma crítica do caráter da luta destas manifestações. Um movimento anti-sistêmico não se reduz apenas a um movimento contra-hegemônico que tenha suas bases materiais no plano econômico. Em acordo com Negri, é mais amplo e invade todos os campos da vida, e por sua vez do próprio sistema-mundo. Fato que nos faz pensar que a luta contra o sistema é mais do que isso e que a totalidade do sistema não se representa pela luta contra a hegemônica econômica do capital.

Neste caso específico, Habermas (1984) também nos ajuda a pensar esta amplitude das lutas anti-sistêmicas. Diferentemente de Marx e Wallerstein, para quem a deformação do mundo da vida decorreria das condições de reprodução material, Habermas considera possível que o sistema se submeta ao conteúdo normativo do mundo da vida, pois há patologias sociais apenas quando o mundo da vida não consegue resistir à colonização, aos ataques dos imperativos sistêmicos. Mesmo estruturas econômicas oligopolíticas não determinam per se, segundo ele, uma coisificação do mundo da vida.

A preocupação central de Habermas (1997) torna-se, a partir disso, a extensão global da aplicação dos direitos humanos, cujo principal obstáculo é visto na soberania do Estado. Implica, assim, a criação no plano internacional de uma ordem jurídica que seja tão coercitiva como o Estado na ordem interna.

Sendo assim, Habermas (1984) vê o conflito nas sociedades ocidentais avançadas não mais na reprodução material, mas sim na reprodução cultural, na integração social e na socialização - uma outra consequiência da separação entre sistema e mundo da vida. Para ele, os meios "poder" e "dinheiro" não bastam mais para enfrentar os problemas sociais, pois "os novos conflitos não são desencadeados por problemas de distribuição, mas sim por questões de gramáticas de formas de vida" (HABERMAS, 1984).

Enquanto que Wallerstein identifica a mercantilização da vida como uma peculiaridade do atual sistema histórico, Sader (2004) evidencia outros valores cultuais, sociais e políticos vendidos pela hegemonia norte-americana. Para 0 autor, o american way of life foi a grande mercadoria vendida por Hollywood, projetando para o mundo os valores norte-americanos - morais, estéticos, culturais, entre outros. Vendeu um imenso mundo de mercadorias mediante seu enorme aparato de propaganda midiática, atrás do qual se inserem as grandes corporações e suas marcas (SADER, 2004).

Se por um lado, há necessidade de reafirmar certos princípios marxistas, sob os quais não devemos abrir mão, por outro lado, há necessidade de compreender 
que a dinâmica da história toma novos rumos. Marx (1956) jogou suas energias para a emancipação social via socialismo naquele contexto histórico em que vivia; no entanto, no contexto atual, vivemos em uma era marcada pelo esgotamento de energias que visem revolucionar o status quo através do socialismo.

Diante disto, na prática, encontramos um sujeito marcado por dualidades. Por um lado, encontramos um sujeito engajado nas lutas sociais mobilizandose contra o sistema, no sentido de romper com a lógica neoliberal; por outro lado, constatamos um sujeito inoperante e impotente aos processos de lutas emancipatórias porque a totalidade dos sujeitos está descrente dos ideais revolucionários e marcada pela apatia política.

Esta dualidade tornou-se um dilema no campo teórico da sociologia política, estabelecendo, assim, um marco "divisor de águas" entre crença e descrença, pessimismo e otimismo, esperança e ceticismo. Este dualismo, que não se confunde com a ambigüidade dos sujeitos, tornou-se um impasse mais teórico do que empírico e carece de uma visão que o incorpore como princípio e ponto de partida para a compreensão dos movimentos anti-sistêmicos, ampliando, assim, a noção de luta social em tempos contemporâneos.

\section{Por uma RessignificaÇão dos Movimentos AnTI-SistÊMICOS}

Os movimentos anti-sistêmicos, caracterizados por Wallerstein (2005), tais como movimentos ecológicos, feministas, de direitos humanos, etc, já estão em constantes diálogos com as esferas públicas, sociedade civil e Estado, muitos deles articulados em redes de movimentos sociais.

Apesar de reconhecer a evidência dos movimentos anti-sistêmicos, o cidadão comum ainda não incorporou as necessidades de mudanças. Neste caso, um dos desafios é estabelecer uma horizontalidade dos movimentos antisistêmicos, pois na medida em que os processos de cooptação, injustiça social e desigualdade fazem parte da lógica do capitalismo, as novas lutas anti-sistêmicas voltam-se mais para a revigoração do status quo do que para a ruptura do modelo vigente. A consciência de mudança social está mais fortemente enraizada no seio da sociedade do que a consciência de ruptura com o capitalismo.

Neste sentido, defende-se uma postura relacional dos movimentos antisistêmicos, pois a sua luta contra o sistema pode ser dentro e fora ao mesmo tempo. 
Esta luta é de fora quando expressa no núcleo das manifestações negando com todas as forças a primazia de uma dominação com bases na economia capitalista. Ao mesmo tempo, é uma luta que trilha por dentro o rompimento com os aspectos de desigualdade, injustiça social e cultural acompanhada dos constantes processos de alienação e coisificação dos sujeitos.

A nova dimensão da noção de movimento anti-sistêmico permite a ampliação da noção de luta de classe por lutas políticas que ganham um aspecto mais subjetivo do que objetivo, na mesma perspectiva de Castells (2002) ao identificar o confronto constante de um sujeito individual e social ao mesmo tempo.

Nesta perspectiva, a "luta" se torna algo constante, que, além de ser representada pela sociedade civil, ONGs, partidos políticos, também se expressa nos momentos limítrofes entre apatia política e violência social, sinalizando a "voz" de um sujeito solapado pelos ditames do capital.

Neste sentido, teoricamente falando, não se vá "nem tanto ao céu nem tanto ao inferno", pois o que antecede as tentativas de propor alternativa é a necessidade, principalmente da sociologia política, em compreender os caminhos que estão sendo trilhados, atentando para as dificuldades, seus equívocos e impasses.

A dificuldade de colocar os sujeitos em uma luta de ruptura com o sistema e de avançarem por uma causa única é explicada pelo próprio Marx (2004), quando afirma que o processo de coisificação impede os sujeitos de avançarem por uma causa única. Cabe lembrar que a tradição materialista, em suas diversas variantes, percebeu justamente em tal observação exterior ao sistema a causa do fenômeno da reificação.

Marx entendeu por fetichismo da mercadoria a ilusão que surge quando relações sociais assumem a forma de relações entre coisas, exteriores às pessoas.

Para Marx (2004, p. 94), os sistemas, apesar de pertencerem às pessoas, assumem o caráter de uma exterioridade coisificante. A vida é coisificada por meio de uma "objetivação fantasmagórica". 0 ser humano é visto como parte mecanizada de um sistema, que parece ter uma existência independente dele. 0 "caráter contemplativo do comportamento capitalista do sujeito" (p.109) impede0 de ter o conhecimento verdadeiro dos sistemas.

Para Wallerstein, a importância e atuação dos movimentos anti-sistêmicos têm como base o materialismo histórico, sua audácia de transformação sistêmica 
é um sinal de que não há mais apostas a serem feitas por e pela hegemonia do capital dominante. Apear de compartilhar da visão sistêmica dos movimentos inserido no contexto do sistema-mundo de Wallerstein, o diferencial crítico que se pretende destacar, deste autor, refere-se a ampliação da noção de movimentos antisistêmicos revelada pelos impactos promovidos pelo sistema para além das bases econômicas; firmando assim uma nova categoria sociológica e ressignificando a própria noção de movimentos sociais.

Contudo, a maior dificuldade é compreender, neste aspecto, diferentemente de Wallerstein, que as lutas sociais não são apenas um momento de transição; ao contrário, elas são transitivas apenas para ceder lugar a uma nova configuração de lutas sociais, quando se considera que a sociedade vai evoluindo em diferentes graus de conflitos sociais, e talvez a questão mais pertinente não esteja relacionada com a busca incessante de um mundo totalmente idealizado pelas igualdades sociais, mas de sabermos: que tipo de luta social a humanidade pretende recriar?

\section{Considerações FinaIs}

Se analisarmos a pergunta de Lênin em "fazer o quê?", perceberemos por se perder no tempo um espírito revolucionário e transformador. As ações sociais estão difusas nos sistemas-mundo marcadas por apatias sociais, manifestações de violência, por reclames de justiça social e reconhecimento mútuo, muitas vezes muito além de necessidades materiais.

Nesta perspectiva, a emergência dos movimentos anti-sistêmicos não apenas possibilita uma nova categoria de movimentos sociais, mas ressignifica as ações das lutas sociais deste novo cenário dos sistemas-mundo, que Wallerstein se refere. 0 diferencial é que estes movimentos ocorrem, em sua magnitude, de dentro para fora, pois não há mais movimentos de choque e negação total a hegemonia capitalista e aos princípios neoliberais.

Os movimentos anti-sistêmicos possuem uma dualidade, no momento em que sua atuação é, ao mesmo tempo, por dentro e fora do sistema, ou seja, é interior quando se luta por reconhecimento, por direitos humanos e quando os atores sociais incorporam todas as facetas do fetichismo da mercadoria, do consumo, dos processos de alienação e coisificação dos sujeitos; e é exógeno quando as manifestações atingem o auge nu e cru de toda a negação de pertence ao sistema. 
Diante disto, há necessidade de repensar o conceito de movimento antisistêmico, pois não há como lutar pela negação do sistema sem deixar de "aceitar" as próprias contradições sistêmicas, fato que gera um descompasso teórico e prático da noção de movimentos anti-sistêmicos. A prática não tem condições de abarcar por completo as visões normativas e necessita de orientações teóricas consistentes para a atuação destes movimentos.

Vamos trilhando os caminhos e percebendo que a vida é feita de dualidades. E, pensando numa abordagem simmeliana, podemos pensar nem num marxismo ortodoxo e nem num pós-modernismo conformista. Neste sentido, antes de propor um ideal de sociedade, um dos desafios constantes para a sociologia é acompanhar as mudanças históricas e, acima disto, compreendê-las. Para que haja uma transformação social das relações dos quotidianos marcados pela influência da economia monetária na vida dos cidadãos comuns, é preciso compreender as imbricações de apatia política, da hipocrisia democrática e dos princípios de coação e coerção da ordem vigente.

No entanto, não há como negar que, para compreender as múltiplas faces das lutas sociais, implica compreender um indivíduo fragmentado, heterogêneo e ambíguo. Esta dualidade é constante quando se percebe que os atores sociais dos movimentos anti-sistêmicos, ao mesmo tempo em que são atores, também são cidadãos comuns, que em alguns momentos também compartilham da apatia política, intercalada com momentos de cólera e negação da lógica do capital.

Simmel (1986) não negava o domínio da economia capitalista, mas propôs ir além ao elencar todos os aspectos de degradação do indivíduo e desenvolvimento de uma cultura objetiva analisando o mundo da economia monetária, do consumo, do crescimento frenético das grandes metrópoles e da busca incessante pelo dinheiro; fatores que demarcam o colapso trágico dos processos de alienação dos indivíduos.

Em se tratando das apropriações teóricas de Marx, cabe valorizarmos aqui, assim como Wallerstein, o grande legado das teorias da alienação, do fetiche da mercadoria e dos processos de coisificação dos sujeitos. A frase célebre,proletários uni-vos, de Marx (1956), éde um momento histórico; no entanto, temos que tomar cuidado com os "perigos do óbvio", pois quem não assume um socialismo em suas múltiplas formas não subentende um neoliberalismo e vice-versa, lutar contra a lógica do capital não, necessariamente, subentende a luta pelo socialismo. 
Marx nos estabelece um terreno para compreendermos as velhas questões conceituais sobre capital, lucro, trabalho, alienação, etc. A pertinência de suas análises ocorre principalmente na sua preocupação pelos caminhos sórdidos que 0 capitalismo nos conduz. No entanto, em pleno século XXI, as mudanças históricas nos conduzem a novos caminhos conceituais que subsidiam as questões que visem compreender com quem se luta e como se luta.

A intencionalidade dos movimentos sociais pode ser considerada totalizante quando todos querem e desejam mudanças. No entanto, os descompassos destas intenções ocorrem quando na prática não há uma horizontalidade de ação efetiva e consistente. Neste sentido, a ação dos movimentos anti-sistêmicos somente será universal quando contiver, na práxis, elementos universais de intencionalidade.

Diante disto, toca aqui um problema de toda teoria da sociedade: a relação entre sujeito e estrutura. No entanto, as estruturas são feitas por indivíduos e neste sentido há que se pensar nos caminhos para a moralidade dos sujeitos e apostar na esperança de compreendermos que a História é feita por ciclos.

\section{REFERÊNCIAS}

ARRIGHI, Giovanni. O longo século XX. Rio de Janeiro: Contraponto, 1994.

CASANOVA, Pablo González. 0 Imperialismo Hoje. Tempo, v. 9, n. 18, Niterói, jun. 2005.

CASTELLS, Manuel. 0 poder da identidade In: . A sociedade em rede. São Paulo: Paz e Terra, 2002. v. 2, p. 21-28.

FRASER, Nancy. Da redistribuição ao reconhecimento? Dilemas da justiça na era pós-socialista. In: SOUZA, Jessé (Org.). Democracia hoje: novos desafios para teoria democrática contemporânea. Brasília: Ed. UNB, 2001.

HABERMAS, Jürgen. Mudança estrutural na esfera pública. Rio de Janeiro: Tempo Brasileiro, 1984.

. A nova intransparência. Dossiê Habermas. Novos Estudos Cebrap, n. 18, São Paulo, set. 1997, p. 103-114.

LUIGI, Ricardo; PENNAFORTE, Charles. Movimentos Anti-Sistêmicos na América Latina: Venezuela e sua "função piemontesa". Boletín de Relaciones 
Internacionales, n. 8, Abr./Mayo, Buenos Aires, 2005.

MARX, Karl. 0 dezoito de Brumário de Luiz Bonaparte. In: Obras escolbidas. Rio de Janeiro: Vitória, 1956. . Manuscritos Econômicos Filosóficos. São Paulo: Martin Claret, 2004. MELUCCI, Alberto. Acción coletctiva, vida cotidiana y democracia. México: El Colegio del México, CES, 1999.

NEGRI, Antonio; HARDT, Michael. Império. Rio de Janeiro: Record, 2000.

NEGRI, Antonio. Opoder constituinte: ensaio sobre as alternativas da modernidade. Rio de Janeiro: DP\&A, 2002.

SADER, Emir. Hegemonias y emancipaciones en el siglo XXI. Ana Esther Ceceña (comp.). Buenos Aires CLACSO, 2004.

SIMMEL, Georg. Sociologia: estudios sobre las formas de socialización. Madrid: Alianza, 1986.

TOURAINE, Alain. Um novo paradigma: para compreender o mundo de hoje. Petrópolis: Vozes, 2006. pt. II, cap. 2.

WALLERSTEIN, Immanuel. Capitalismo histórico e civilização capitalista. Rio de Janeiro: Contraponto, 2001.

. A difícil transição ou o inferno na terra? In: WALLERSTEIN, Immanuel. Utopística: ou as decisões históricas do século XXI. Rio de Janeiro: Vozes, 2003. . El Moderno Sistema Mundial. 4. ed. México: Siglo XXI, 1988. v.1. . Análise dos sistemas mundiais. In: GIDDENS, Anthony. Teoria Social Hoje. São Paulo: UNESP, 1996. p. 447-470.

. 0 que significa hoje ser um movimento anti-sistêmico. In: LEHER, Roberto; SETÚBAL, Mariana (0rg.). Pensamento crítico e movimentos sociais. São Paulo: Cortez, 2005.

WIEVIORKA, Michel. Em que mundo viveremos? São Paulo: Perspectiva, 2006. 